LACK, C. H. (1952). J. gen. Microbiol. 7, 144

\title{
A Simple Hot Box for Microcultures
}

\author{
By C. H. LACK \\ Institute of Orthopaedics, Royal National Orthopaedic Hospital, \\ Stanmore, Middlesex
}

SUMMARY: The invention of glass electrothermal heating tape provides a simple method for heating a hot box or incubator without the expense and trouble of a water jacket. An outfit is described for observing microscopically and photographing cultures at controlled temperatures over long periods.

The accompanying photographs illustrate a hot box which we have made in the laboratory out of the wooden case in which the microscope was supplied. Eighteen inches of electrothermal heating tape (Electrothermal Engineering Ltd., supplied by A. Gallenkamp and Co., London), are fixed around the inside of the box; leads from this pass through a Sunvic thermostat, the control of which is on the outside. Two thermometers pass through the sides of the box; they are protected outside by metal shields. A hole is cut in the back of the box and a glass chamber containing water is inserted to allow illumination from outside without heat loss.

In the outfit illustrated here (Pl. 1, fig. 1), a Cooke Universal microscope is shown, with a culture preparation mounted for growth and for observation by phase contrast. There are two sources of illumination at the back of the box: (i) an $8 \mathrm{~V}$. Cooke lamp which slides in and out of the box at the back; (ii) a mercury vapour lamp that is fixed in a well behind the box. For ordinary observation the $8 \mathrm{~V}$. lamp is used, but when more light is required for photography, the $8 \mathrm{~V}$. lamp is taken out and the mercury vapour lamp which is already in proper alinement is used instead. Pl. 1, fig. 2, also shows a Perspex front which is used to help maintain a constant temperature when observations are to be made for a long time.

This hot box has been in continuous use for 9 months and we have had no trouble with it. A little steam and odour come from the thermal tape when first used, but this stops after $2-\mathbf{3 ~ h r}$. As this tape may be obtained in a range of wattage/foot, it obviously has many laboratory uses.

I wish to thank Mr R. J. Whitley for the photographs.

\section{EXPLANATION OF PLATE}

Fig. 1. A microscope in position in its own case showing the thermal tape, the white material on the left.

Fig. 2. Shows the Sunvic control, one thermometer, and the mercury vapour lamp. The plastic screen can be seen in the photograph.

(Received 18 February 1952) 
Journal of General Microbiology, Vol. 7, Nos. $1 \& 2$
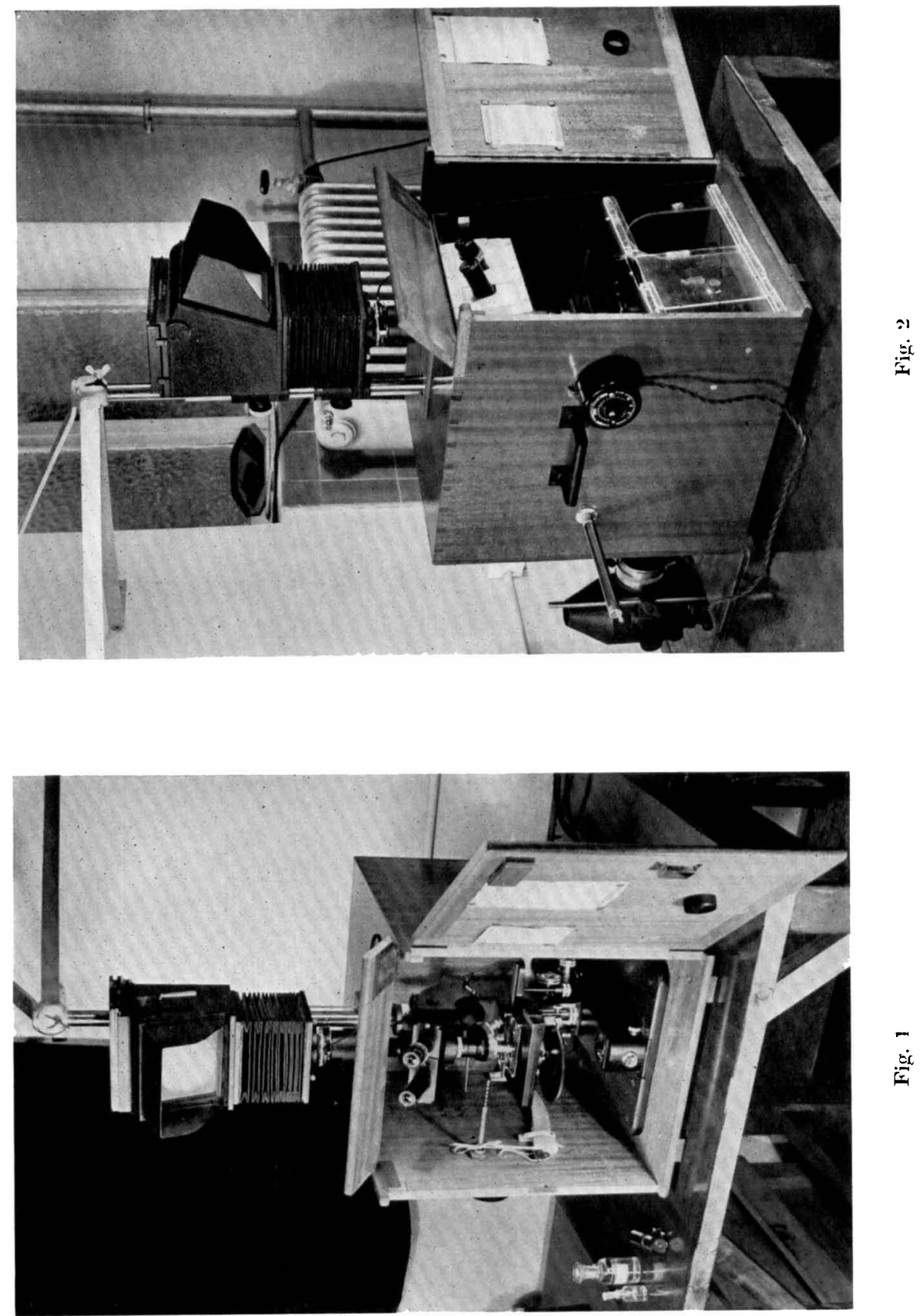

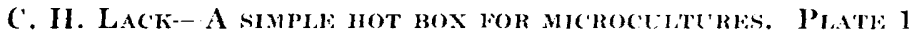

